\title{
Inhibitory Effect of Centipede Scolopendra Extract on Gallbladder Carcinoma via Up-regulation of PUMA
}

\section{Cheng Yan}

Central South University

\section{Yangyan Xiao}

Central South University

Jingfen Ji

Central South University

Zhide Liu

Central South University

Weichang Zhang

Central South University

\section{Zonglin Chen}

Central South University

\section{Qinglong Li}

Central South University

Wenwu Cai ( $\sim$ caiwenwu1986@csu.edu.cn )

Central South University

\section{Research}

Keywords: Centipede scolopendra extract, gallbladder carcinoma, apoptosis, PUMA, siRNA

Posted Date: July 26th, 2021

DOI: https://doi.org/10.21203/rs.3.rs-730042/v1

License: (c) (1) This work is licensed under a Creative Commons Attribution 4.0 International License. Read Full License 


\section{Abstract}

Background: To observe the effect of centipede scolopendra extract on gallbladder carcinoma (GBC) and further investigate its underlying mechanism.

Methods: The GBC cell line GBC-SD was purchased and cultured. Small interfering RNA (siRNA) was constructed. The mRNA expression levels of PUMA were measured by reverse transcription-quantitative PCR (RT-qPCR) and protein expression levels of p53, PUMA, Bax and Bcl-2 were measured by western blotting respectively. Viability and proliferation were detected using MTT and colony formation assays respectively. The apoptosis rate was determined by Annexin-V-FITC/PI double staining.

Results: The GBC-SD cell line was successfully obtained and cultured. MTT and colony formation assays demonstrated that the viability and proliferation of GBC-SD cells could be markedly inhibited by centipede scolopendra extract in a concentration-dependent manner in the limited concentration range. Following pretreatment with centipede scolopendra extract, RT-qPCR demonstrated that the expression levels of PUMA were markedly increased in the GBC-SD cells, and western blotting showed that the high expression of PUMA was accompanied by upregulation of Bax and downregulation of p53 and Bcl-2 in the GBC-SD cells. However, this effect has proved hard to reproduce after PUMA-siRNA. Flow cytometry revealed that the apoptosis rate was $9.8 \pm 2.2 \%, 25.3 \pm 3.6 \%, 10.6 \pm 2.0 \%$, and $13.5 \pm 2.4 \%$ in control group, centipede scolopendra extract group, PUMA-siRNA group, and centipede scolopendra extract combined with PUMA-siRNA group respectively.

Conclusions: Centipede scolopendra extract could induce the apoptosis of GBC-SD cells by promoting the PUMA-Bax signaling pathway. It could serve as a potential novel therapy for GBC in clinical practice.

\section{Background}

Gallbladder carcinoma (GBC) is the most common type of malignant tumor of the biliary tract, and it is the fifth most common type of malignant tumor of the digestive tract ${ }^{[1-2]}$. Early diagnosis and radical surgical resection, which is the most effective and preferred treatment method for patients with GBC, may enable patients to have an improved long-term survival ${ }^{[3-4]}$. However, due to its atypical early symptoms, frequently rapid and silent progression, most patients have been at an advanced stage when diagnosed. Only $15 \%-47 \%$ of the patients have the chance to undergo radical resection ${ }^{[5-6]}$. The prognosis of patients with GBC is poor. A previous study has reported that the median survival time of patients with $\mathrm{GBC}$ is only 6 months, and the overall 5 -year survival rate is not more than $5 \%{ }^{[7]}$. Most patients with GBC eventually succumb to metastatic disease ${ }^{[8]}$.

Chemotherapy is an important complementary therapy. However, Due to the low sensitivity to numerous chemotherapeutic drugs, the effect of chemotherapy in GBC is unsatisfactory ${ }^{[9]}$. It is urgently necessary to explore and develop novel drugs to improve the efficacy and the prognosis of patients with GBC. As a traditional Chinese medicine, centipede scolopendra has been widely used in clinical practice for 
thousands of years. In recent years, a study has reported that centipede scolopendra extract has extensive biological activities, such as anti-inflammatory, anti-oxidation, anti-allergic, and anti-convulsant

etc $^{[10]}$. Besides, several studies have reported anti-tumor effect of centipede scolopendra extract including against epidermoid carcinoma and human embryonic kidney 293 cells $^{[11]}$, human breast tumor ${ }^{[12]}$, hepatocarcinoma ${ }^{[13]}$ and pancreatic cancer ${ }^{[14)}$. However, the effect of centipede scolopendra extract on gallbladder carcinoma have not been elucidated.

PUMA gene is located on chromosome 19q, spans a 119-kb length, encodes a 193-amino-acid protein, and contains $\mathrm{Bcl}-2$ homology domain 3 (BH3) which presents in many apoptotic factors of $\mathrm{Bcl}-2$ family. As a strong inducer of apoptosis, the upregulation of PUMA could activate Bax by translocating Bax into the mitochondrial. Besides, it also could indirectly activate Bax by displacing Bax and binding the antiapoptotic protein $\mathrm{Bcl}-2 / \mathrm{Bcl}-\mathrm{xL}$ to relieve the inhibition of $\mathrm{Bcl}-2 / \mathrm{Bcl}-\mathrm{xL}$ on $\mathrm{Bax}$. These could markedly promote the apoptosis of tumor cells ${ }^{[15]}$.

Taking advantage of the traditional medicine and exploring effective anti-tumor components may improve the efficacy of chemotherapy in GBC. In the present study, the effects of centipede scolopendra extract on GBC were preliminarily investigated, and the potential underlying mechanism was further elucidated.

\section{Methods}

\section{Extract of Centipede Scolopendra}

The centipede Scolopendra specimens were purchased from Changsha Jiuzhitang Pharmaceutical Co., Ltd in Hunan province of China. The specimens were identified as authentic by the Department of traditional Chinese medicine of our hospital where a voucher specimen was deposited. The centipede scolopendra was crushed into fine powder. First, $50 \mathrm{~g}$ specimens were decocted in $1500 \mathrm{ml}$ alcohol solution ( $3 / 2$ by $\mathrm{v} / \mathrm{v}$; alcohol/water) for $1 \mathrm{~h}$, followed by filtering and collection of the filtrate concentrate. Second, $750 \mathrm{ml}$ alcohol solution ( $3 / 2 \mathrm{by} \mathrm{v} / \mathrm{v}$; alcohol/water) was added into the filter residue, and the aforementioned procedures were repeated. Third, the two filtrate concentrates were combined, filtered once again and then evaporated to $25 \mathrm{ml}$. Finally, the stock solution $(2 \mathrm{~g} / \mathrm{ml}, 25 \mathrm{ml})$ was bathed in water at $80^{\circ} \mathrm{C}$ for 30 min with intermittent sterilization for 3 consecutive days. Subsequently, the samples were centrifuged at $1000 \mathrm{R} / \mathrm{min}$ for $10 \mathrm{~min}$ and stored at $-20^{\circ} \mathrm{C}$. When in use, the sterile normal saline was added to $400 \mathrm{mg} / \mathrm{ml}$ and stored at $4{ }^{\circ} \mathrm{C}$ and the bacteria were removed by suction. The rotary evaporator was used to concentrate the extract ${ }^{[16]}$.

\section{Cell culture}

The GBC-SD cell line was supplied by the Institute of Biochemistry and Cell Biology of the Chinese Academy of Sciences (Shanghai, China). The cells were cultured in Dulbecco's modified Eagle's medium (Gibco BRL, Grand Island, NY, USA) supplemented with 10\% fetal bovine serum (HyClone, Logan, UT, 
USA), $100 \mathrm{U} / \mathrm{ml}$ penicillin (Invitrogen, Carlsbad, CA, USA) and $100 \mathrm{U} / \mathrm{ml}$ streptomycin (Invitrogen, Carlsbad, CA, USA). The cells were cultured with $5 \% \mathrm{CO}_{2}$ at saturated humidity at $37^{\circ} \mathrm{C}$.

\section{MTT assay}

GBC-SD cells in the logarithmic growth phase were homogeneously transferred to a 96 -well plate $\left(2 \times 10^{4}\right.$ cells/well). After $24 \mathrm{~h}$ of culture in complete medium, the cells were treated with centipede scolopendra extract at concentrations of $3.125 \mathrm{mg} / \mathrm{ml}, 6.250 \mathrm{mg} / \mathrm{ml}, 12.500 \mathrm{mg} / \mathrm{ml}, 25.000 \mathrm{mg} / \mathrm{ml}$ and $50 \mathrm{mg} / \mathrm{ml}$ respectively. After 24 h, 48 h, and 72 h, each hole was added with 10\% FBS and 20 ul MTT solution (5 $\mathrm{mg} / \mathrm{ml}$ ) (Sigma-Aldrich, St. Louis, MO, USA). Culturing for $4 \mathrm{~h}$ at $37^{\circ} \mathrm{C}$, after discarding the supernatant, each hole was added 150 ul DMSO (Sigma-Aldrich, St. Louis, MO, USA). After shaking for 10 min, 100 ul cell suspensions was put into another 96-well plate with 100 ul DMSO solution as a control. The Cell Proliferation Reagent Kit I (MTT; Roche Applied Science) was used at $37^{\circ} \mathrm{C}$ for $4 \mathrm{~h}$ to determine the cell viability. The absorbance values were determined at $490 \mathrm{~nm}\left(\mathrm{~A}_{490}\right)$ using a spectrophotometer (Omega Bio-Tek, Inc.).

The $\mathrm{A}_{490}$ were measured in the experimental group and control group, and the cell inhibition rate was calculated using the formula as follows: the inhibition rate $(\%)=\left[1-\left(A_{490}\right.\right.$ mean value of experimental group $/ \mathrm{A}_{490}$ mean value of control group)] $\times 100 \%$. According to the changes of cell inhibition in the different concentration of centipede scolopendra extract and treatment duration, the optimum concentration and treatment duration of centipede scolopendra extract were confirmed. The experiment was repeated 3 times and the mean value was used to draw the cell growth curve

\section{Colony formation assay}

The cells were treated with centipede scolopendra extract as aforementioned. After $48 \mathrm{~h}$ of treatment, the cells were harvested and counted after trypsinization. A total of 500 cells/well were placed in a 6-well plate and cultured at $37^{\circ} \mathrm{C}$. The medium was refreshed once every 3 days. After 14 days, the cells were washed with $1 \times$ PBS, fixed with $3.7 \%$ methanol, and stained with $0.1 \%$ crystal violet at $37^{\circ} \mathrm{C}$ for 10 min (Sigma-Aldrich, St. Louis, MO, USA). Visible colonies were manually counted using an optical microscope (Olympus Corporation) (each colony contains at least 50 cells).

\section{PUMA-siRNA synthesis}

According to the GenBank database, the sequences of primers were designed in Table 1. Three interference siRNAs and one negative control siRNA were synthesized and determined no homology with other nonrelated genes by Genechem Co., Ltd (Table 1$)$. The cells were inoculated in a 6 -well plate $\left(5 \times 10^{5}\right.$ cells/well), and the lipofectamine 2000 reagent (Invitrogen, Carlsbad, CA, USA) was used for transfection with the siRNAs at a concentration of $120 \mathrm{nM}$ according to the manufacturer's instructions. The cells were divided into five groups as follows: PUMA-siRNA-1 group, PUMA-siRNA-2 group, PUMA-siRNA-3 group, PUMA-siRNA-NC group, and normal group. After $24 \mathrm{~h}$, total RNA was extracted and amplified with RT-qPCR, then the more efficient PUMA-siRNA was selected to perform the subsequent experiments. 
Table 1

the sequences of PUMA primers, GAPDH primers and three siRNA

\begin{tabular}{|c|c|}
\hline Classification & Sequences $\left(5^{\prime}-3^{\prime}\right)$ \\
\hline \multirow[t]{2}{*}{ PUMA } & Forward: TGAAGAGCAAATGAGCCAAACG \\
\hline & Reverse: CAGAGCACAGGATTCACAGTCT \\
\hline \multirow[t]{2}{*}{ GAPDH } & Forward: TGACTTCAACAGCGACACCCA \\
\hline & Reverse: CACCCTGTTGCTGTAGCCAAA \\
\hline \multirow[t]{2}{*}{ PUMA-siRNA-1 } & Forward: CGUGUGACCACUGGCAUUCdTdT \\
\hline & Reverse: GAAUGCCAGUGGUCACACGdTdT \\
\hline \multirow[t]{2}{*}{ PUMA-siRNA-2 } & Forward: UCUCAUCAUGGGACUCCUGdTdT \\
\hline & Reverse: CAGGAGUCCCAUGAUGAGAdTdT \\
\hline \multirow[t]{2}{*}{ PUMA-siRNA-3 } & Forward: CAUGGGACUCCUGCCCUUAdTdT \\
\hline & Reverse: UAAGGGCAGGAGUCCCAUGdTdT \\
\hline \multirow[t]{2}{*}{ PUMA-SIRNA-NC } & Forward: UUCUCCGAACGUGUCACGUdTdT \\
\hline & Reverse: ACGUGACACGUUCGGAGAAdTdT \\
\hline
\end{tabular}

The stability of selected PUMA-siRNA in the presence of centipede scolopendra extract was detected. The cells were divided into four groups as follows: PUMA-siRNA group, PUMA-siRNA combined with centipede scolopendra extract group, centipede scolopendra extract group and normal control group. After $24 \mathrm{~h}$, total RNA was extracted and amplified with RT-qPCR.

\section{Flow cytometry}

The cells were inoculated in a 6 -well plate $\left(1 \times 10^{5}\right.$ cells/well $)$ and divided into four groups: PUMA-siRNA group, PUMA-siRNA combined with centipede scolopendra extract group, centipede scolopendra extract group, and control group. After treatment with different experimental materials according to the grouping, the cells were harvested, washed twice, resuspended in binding buffer, and stained with the Annexin $\mathrm{V}$ and PI solution at room temperature for $30 \mathrm{~min}$. The Annexin V-FITC apoptosis detection kit (Beckman Coulter, Brea, CA, USA) was used to detect the apoptosis of cells by Annexin V-FITC and PI double staining according to the manufacturer's instructions. The analysis was performed using a BD FACSAria ${ }^{\text {TM }}$ II flow cytometer (Becton, Dickinson and Company), and the data were analyzed using CellQuest Pro software (version 5.1; Becton, Dickinson and Company).

\section{RT-qPCR}

Following treatment with centipede scolopendra extract and/or PUMA-siRNA, total RNA was exacted from GBC-SD cell lines using Trizol Reagent (Invitrogen, Carlsbad, CA, USA), which were then treated with DNase I (Invitrogen, Carlsbad, CA, USA) for purification according to the manufacturer's instructions. 
Reverse transcription was performed at $42^{\circ} \mathrm{C}$ for 60 min using miRcute miRNA First-Strand cDNA Synthesis Kit (TaKaRa biotechnology, Dalian, China) according to the manufacturer's instructions. qPCR was performed using the SYBR $\circledast$ Green PCR detection kit (TaKaRa biotechnology, Dalian, China) in a 7500 Real-Time PCR system (Applied Biosystems; Thermo Fisher Scientific, Inc.) according to the manufacturer's instructions. The sequences of the primers were summarized in Table 1 . The $2^{-\Delta \Delta \mathrm{Ct}}$ method was used to calculate the relative expression level of target gene ${ }^{[17]}$. The GAPDH was used as an internal control.

\section{Western blot analysis for the protein expression of p53, PUMA, Bax and Bcl-2}

Following treatment with centipede scolopendra extract and/or PUMA-siRNA, total protein was extracted using RIPA lysis buffer (50 mM Tris pH 8.0, $120 \mathrm{mM} \mathrm{Nacl,} \mathrm{0.5 \%} \mathrm{sodium} \mathrm{deoxycholate,} 0.5 \%$ NP-40, 0.1\% SDS, $1 \mathrm{mM}$ EDTA, $50 \mathrm{mM} \mathrm{NaF}, 1 \mathrm{mM} \mathrm{Na} 2 \mathrm{VO} 4,1 \mathrm{mM}$ PMSF, and $2 \mathrm{ug} / \mathrm{ml}$ aprotinin) on ice for $30 \mathrm{~min}$. The protein concentration was determined by BCA assay, and $50 \mu \mathrm{g}$ protein/lane was separated using the $10 \%$ sodium dodecyl sulfate-poly-acrylamide gel electrophoresis at $120 \mathrm{~V}$ for $60 \mathrm{~min}$, which were then transferred onto polyvinylidene difluoride (PVDF) membranes. The membranes were blocked with the $5 \%$ non-fat milk in TBST (10 mM Tri pH 7.4, $150 \mathrm{mM} \mathrm{NaCl}$ and 0.1\% Tween 20) at room temperature for 60 min and incubated with prepared primary antibodies against PUMA (1:1,000; cat. no. ab33906), p53 (1:500; cat. no. ab131442), Bax (1:1,000; cat. no. ab32503), Bcl-2 (1:2,000; cat. no. ab182858) (all from Abcam) and $\beta$-actin (1:1,000; cat. no. A2228; Sigma-Aldrich; Merck KGaA) at $4^{\circ} \mathrm{C}$ for $12 \mathrm{~h}$ with gentle rocking. Next morning, the membranes were washed three times in TBST for $5 \mathrm{~min}$, and then incubated with HRP conjugated goat anti-rabbit IgG (1:2,000; cat. no. sc-2004) or anti-mouse lgG (1:2,000; cat. no. sc-2005) (both from Santa Cruz Biotechnology, Inc.) secondary antibody at $37^{\circ} \mathrm{C}$ for $60 \mathrm{~min}$. The protein bands were visualized with an enhanced chemiluminescence system (Thermo Fisher Scientific, Inc.) according to the manufacturer's instructions. The Gel Doc 2000 imaging system (Bio-Rad Laboratories, Inc.) was used for densitometric analysis of the protein bands with ImageJ software (version 1.8.0.112; National Institutes of Health) according to the manufacturer's instructions. $\beta$-actin was used as the internal control.

\section{Statistical analysis}

SPSS v17.0 software (SPSS, Inc., Chicago, IL, USA) was used to perform statistical analyses. All data were expressed as the mean \pm standard deviation. The differences were analyzed using $T$ test for two groups and One-way Analysis of Variance (ANOVA) with the Bonferroni correction for multiple groups. $P<$ 0.05 was considered statistically significant. All experiments were repeated at least 3 times.

\section{Results}

\section{Optimum concentration and treatment duration of centipede scolopendra extract}


The GBC-SD cells were treated with centipede scolopendra extract at concentrations of $3.125 \mathrm{mg} / \mathrm{ml}$, $6.250 \mathrm{mg} / \mathrm{ml}, 12.500 \mathrm{mg} / \mathrm{ml}, 25.000 \mathrm{mg} / \mathrm{ml}$ and $50.000 \mathrm{mg} / \mathrm{ml}$ for $24 \mathrm{~h}, 48 \mathrm{~h}$ and $72 \mathrm{~h}$ respectively. The results shown in Fig. 1 revealed that there was no significant difference among groups treated with different concentrations of centipede scolopendra extract in the first $24 \mathrm{~h}$. At $48 \mathrm{~h}$ after treatment with centipede scolopendra extract at the concentration of $12.500 \mathrm{mg} / \mathrm{ml}$, the inhibition rate markedly increased to $59.68 \pm 4.85 \%$ and continued to slowly increase with the growing concentration, however, excessive toxicity was observed at the concentration of $50.000 \mathrm{mg} / \mathrm{ml}$ and all cells were dead. The toxicity was observed as early as at the concentration of $12.500 \mathrm{mg} / \mathrm{ml}$ after treatment for $72 \mathrm{~h}$, and when the concentration reached $25.000 \mathrm{mg} / \mathrm{ml}$, all cells died. In this study, the concentration of 12.500 $\mathrm{mg} / \mathrm{ml}$ and treatment duration of $48 \mathrm{~h}$ were selected for the subsequent experiments.

\section{Designation of PUMA-siRNA}

The cells were transfected with PUMA-siRNA-1, PUMA-siRNA-2, PUMA-siRNA-3, and PUMA-siRNA-NC respectively using lipofectamine 2000 for $24 \mathrm{~h}$, and then total RNA was extracted, amplified and measured. The results shown in Fig. 2A demonstrated that PUMA-siRNA-2 was more efficient, and the silencing efficiency could reach $71.85 \pm 6.68 \%$ in the PUMA-siRNA-2 group. Therefore, the PUMA-siRNA-2 was selected to use in the next experiment.

The stability of PUMA-siRNA-2 in the presence of centipede scolopendra extract was proved in Fig. $2 \mathrm{~B}$. The silencing efficiency of PUMA-siRNA-2 group was almost equal to that of PUMA-siRNA-2 combined with centipede scolopendra extract group.

\section{Centipede scolopendra extract inhibits viability and proliferation of GBC-SD cells}

To test the effect of centipede scolopendra extract on cell growth, the GBC-SD cells were treated with extract at concentrations of $3.125 \mathrm{mg} / \mathrm{ml}, 6.250 \mathrm{mg} / \mathrm{ml} 12.500 \mathrm{mg} / \mathrm{ml}$ and PUMA-siRNA-NC combined with centipede scolopendra extract at concentrations of $12.500 \mathrm{mg} / \mathrm{ml}$ for $12 \mathrm{~h}, 24 \mathrm{~h}$ and $48 \mathrm{~h}$. The results shown in Fig. 3A demonstrated that the growth of GBC-SD cells were markedly inhibited by treatment with centipede scolopendra extract in a concentration-dependent manner in the limited concentration range according to the MTT assay.

Colony formation assay was performed to verify the effect of centipede scolopendra extract on proliferation ability of GBC-SD cells. As shown in Fig. 3B, the proliferation ability of GBC-SD cell was markedly suppressed by treatment with centipede scolopendra extract in a concentration-dependent manner in the limited concentration range.

\section{Centipede scolopendra extract promotes cell apoptosis}

Following treatment with centipede scolopendra extract and/or PUMA-siRNA, the apoptosis of GBC-SD cells was detected by flow cytometry. As shown in Fig. 4, the GBC-SD cell apoptosis rate was $9.8 \pm 2.2 \%$ in the control group, but this sharply increased to $25.3 \pm 3.6 \%$ in the centipede scolopendra extract group $(P$ 
<0.01). Nevertheless, when PUMA-siRNA-2 was used to block PUMA expression, the GBC-SD cell apoptosis rate was $10.6 \pm 2.0 \%$ in the PUMA-siRNA group compared with $13.5 \pm 2.4 \%$ in the PUMA-siRNA combined with centipede scolopendra extract group $(P>0.05)$.

\section{Underlying mechanism of Centipede scolopendra extract on GBC-SD}

To further uncover the potential mechanism of the inhibitory effect of centipede scolopendra extract on GBC-SD cells, RT-qPCR was performed to detect the expression of PUMA. As shown in Fig. 5, compared with the control group, the PUMA expression was markedly increased in the experiment groups $(P<0.05)$. Western blotting was performed to detect the expressions of several key regulators. As shown in Fig. 6 , compared with the control group, the PUMA and Bax expression were markedly increased while the p53 and $\mathrm{Bcl}-2$ expression were markedly decreased following treatment with centipede scolopendra extract in a concentration-dependent manner in the limited concentration range. These results demonstrated that the PUMA-Bax signaling pathway may contribute to the inhibitory effect of centipede scolopendra extract on the GBC-SD cells.

\section{Discussion}

As a common type of cancer with an annually increasing occurrence rate, GBC has unsatisfactory outcomes of current therapies, which mainly included surgery, chemotherapy, radiotherapy, and immunotherapy and an extremely poor prognosis ${ }^{[7-8]}$. This is not only due to its high malignancy and a lack of early specific diagnostic methods which lead to most patients at an advanced stage when diagnosed, but GBC also usually present low sensitivity to chemotherapy and radiation ${ }^{[9]}$. Additonally, the vast majority of patients cannot afford the expensive cost of immunotherapy drugs which are generally not covered by medical insurance in China. All these factors lead to the poor outcome of patients with GBC in China. It is imperative to identify novel and effective treatments for patients with GBC.

As a traditional Chinese medicine, centipede scolopendra has been used to treat a series of conditions such as childhood convulsion, diphtheria, poisonous nodules, spasm, and seizure for thousands of years

in China ${ }^{[18-19]}$. There are venom glands in the first two limbs of centipede scolopendra, which contain many species of chemical constituents such as histamine, sero-tonin, polysaccharids, polypeptides and lipids ${ }^{[20-21]}$. Previous studies have demonstrated that they present different biochemical and pharmacological properties ${ }^{[10]}$. Among these, the effect to inhibit tumor growth has been widely concerned $^{[11-14,22]}$.

In the present study, the authors have demonstrated that centipede scolopendra extract served a notable role in inducing cell apoptosis to inhibit growth of GBC-SD cells. The results revealed that viability and proliferation of GBC-SD cells were markedly inhibited by centipede scolopendra extract in a 
concentration-dependent manner in the limited concentration range. This suggested that centipede scolopendra extract could serve as a novel treatment for patients with GBC in clinical practice.

Cell apoptosis plays a critical role in oncogenesis and progression and inducing apoptosis is a very common way of anti-tumor treatment ${ }^{[23]}$. Tamm has reported several mechanisms of apoptosis contributing to oncotherapy as follows: i) promoting growth-factor-independent cell death; ii) interfering with bypassing of cell-cycle checkpoints; and iii) enhancing sensitivity of tumor cells to immune-based cytotoxicity ${ }^{[24]}$. Therefore, the Annexin V-FITC and PI double staining assay was used to detect the apoptotic effect of centipede scolopendra extract on GBC-SD cells. The results demonstrated that centipede scolopendra extract could markedly induce apoptosis of GBC-SD cells. However, the effect of inducing apoptosis could be markedly inhibited by PUMA-siRNA, which suggested that centipede scolopendra extract may induce apoptosis of GBC-SD cells via the PUMA signaling pathway.

The biological functions of the PUMA gene has been introduced in detail in the previous article ${ }^{[11]}$. The p53-dependent and non-dependent pathways play key roles in PUMA inducing cell apoptosis. Previous studies have reported that the mechanism of PUMA-induced apoptosis may include the followings: i) PUMA and BCL-2/Bcl2xl combine to produce an inhibitory effect on Bax/Bak in the normal or tumor cells; ii) PUMA combines with $p 53 / B c 12 x l$ so that $p 53$ could be set free, which further activates Bax to induce cell apoptosis; and iii) PUMA directly binds to Bax/Bak to change its conformation, and then Bax is activated to induce cell apoptosis ${ }^{[25-28]}$.

In order to gain further insights into the mechanism of centipede scolopendra extract- induced GBC-SD cell apoptosis, further experiments were performed. Since the Bcl-2 family plays a vital role in the process of cell apoptosis ${ }^{[29-31]}$, the expressions of p53, PUMA, Bax and Bcl-2 were detected by western blotting. The results revealed that centipede scolopendra extract could markedly up-regulate the expressions of PUMA and Bax, while it markedly down-regulate the expressions of p53 and Bcl-2 in a concentrationdependent manner in the limited concentration range. This indicated that inducing apoptotic effect of centipede scolopendra extract was closely associated with the PUMA-Bax signaling pathway, which was consistent with the results of flow cytometry. However, further research are still required to clarify the other potential mechanisms of the regulatory process.

In this study, the inhibitory effect of centipede scolopendra extract on GBC and its underlying mechanism were only investigated by cell experiments in vitro. More studies will be carried out to confirm the results by animal experiments in vivo in the following research.

\section{Conclusion}

In summary, the present study demonstrated that centipede scolopendra extract could induce GBC-SD cell apoptosis via up-regulation of PUMA and Bax expression, correlating with down-regulation of p53 and Bcl-2 expression. This contributed to the inhibition by centipede scolopendra extract on GBC-SD cell 
growth. The present study offered effective data for centipede scolopendra extract as a potential novel strategy against GBC in clinical practice.

\section{Abbreviations}

Gallbladder carcinoma, GBC;

Reverse transcription-quantitative PCR, RT-qPCR;

Bcl-2 homology domain 3, BH3;

United States of America, USA;

PUMA-siRNA-NC group, PUMA-siRNA-Negative Control group;

polyvinylidene difluoride, PVDF;

One-way Analysis of Variance, ANOVA;

\section{Declarations}

\section{Ethics approval and consent to participate}

Not applicable.

\section{Consent for publication}

Not applicable.

\section{Availability of data and materials}

The datasets used and/or analysed during the current study are available from the corresponding author on reasonable request.

\section{Competing interests}

The authors declare that they have no competing interests.

\section{Funding}

This work was supported by the National Natural Science Foundation of China, Beijing (Grant No. 81703767, W.C and No. 81700809, Y.X) and the Hunan Natural Science Foundation of China, Changsha (Grant No. 2019JJ50891, W.C and No. 2020JJ5839, Y.X).

\section{Authors' contributions}


WC conceived and designed the study. CY, YX and JJ obtained the cell lines and were the major contributors in acquiring the data. $\mathrm{CY}$ and $\mathrm{YX}$ performed the cell experiments and drafted the manuscript. ZL, WZ and ZC analyzed and interpreted the data. QL and WC revised the manuscript. CY, YX and WC confirm the authenticity of all the raw data. All authors read and approved the final manuscript.

\section{Acknowledgements}

Not applicable.

\section{References}

1. Kanthan R, Senger JL, Ahmed S, et al. Gallbladder Cancer in the 21st Century. J Oncol 2015: 967472.

2. Varshney S, Butturini G, Gupta R. Incidental carcinoma of the gallbladder. Eur J Surg Oncol. 2002;28:4-10.

3. Kakaei F, Beheshtirouy S, Nejatollahi SM, et al. Surgical treatment of gallbladder carcinoma: a critical review. Updates Surg. 2015;67:339-51.

4. Cziupka K, Partecke LI, Mirow L, et al. Outcomes and prognostic factors in gallbladder cancer: a single-centre experience. Langenbecks Arch Surg. 2012;397:899-907.

5. Lazcano-Ponce EC, Miquel JF, Munoz N, et al. Epidemiology and molecular pathology of gallbladder cancer. CA Cancer J Clin. 2001;51:349-64.

6. Mekeel KL, Hemming AW. Surgical management of gallbladder carcinoma: a review. J Gastrointest Surg. 2007;11:1188-93.

7. Levy AD, Murakata LA, Rohrmann CA Jr. Gallbladder carcinoma: radiologicpathologic correlation. Radiographics. 2001;21(questionnaire):295-314. 549-555.

8. Butte JM, Matsuo K, Gonen M, et al. Gallbladder cancer: differences in presentation, surgical treatment, and survival in patients treated at centers in three countries. J Am Coll Surg. 2011;212:5061.

9. Stein A, Arnold D, Bridgewater J, et al. Adjuvant chemotherapy with gemcitabine and cisplatin compared to observation after curative intent resection of cholangiocarcinoma and muscle invasive gallbladder carcinoma (ACTICCA-1 trial) - a randomized, multidisciplinary, multinational phase III trial. BMC Cancer. 2015;15:564.

10. Stankiewicz M, Hamon A, Benkhalifa R, et al. Effects of a centipede venom fraction on insect nervous system, a native Xenopus oocyte receptor and on an expressed Drosophila muscarinic receptor. Toxicon. 1999;37:1431-45.

11. Ma W, Zhang D, Zheng L, et al. Potential roles of Centipede Scolopendra extracts as a strategy against EGFR-dependent cancers. Am J Transl Res. 2015;7:39-52.

12. Bhagirath $T$, Chingtham $B$, Mohen $Y$. Venom of a hill centipede Scolopendra viridicornis inhibits growth of human breast tumor in mice. Indian J Pharmacol. 2006;38:291-2. 
13. Tian BZ, Pi ZM, Liu W. Effects of extractive liquid oleosa from centipede on proliferation of hepatocarcinoma cells. China Journal of Modern Medicine. 2002;4:55-6.

14. Cai WW, Li QL, Miao XY, et al. Study on the therapeutic effect of centipede extract on pancreatic cancer in rats. Journal of Chinese Physician. 2013;12:1646-9.

15. Cai W, Li Q, Yang Z, et al. Expression of p53 upregulated modulator of apoptosis (PUMA) and C-myb in gallbladder adenocarcinoma and their pathological significance. Clin Transl Oncol. 2013;15:81824.

16. Liu XP, Zhong DW. Study on the mechanisms of tumor inhibitory effect of centipede extraction on heterotopic grafting hepatocellular carcinoma in nude mice. Chin J General Surg. 2010;19:164-8.

17. Livak KJ, Schmittgen TD. Analysis of relative gene expression data using real-time quantitative PCR and the 2(-Delta Delta C(T)) method. Methods. 2001;25:402-8.

18. Moon SS, Cho NS, Shin J, et al. a Cytotoxic Alkaloid from the Centipede Scolopendra subspinipes. J Nat Prod. 1996;59:777-9.

19. Undheim EAB, King GF. On the venom system of centipedes (Chilopoda), a neglected group of venomous animals. Toxicon. 2011;57:512-24.

20. Gomes A, Datta A, Sarangi B, et al. Isolation, purification \& pharmacodynamics of a toxin from the venom of the centipede Scolopendra subspinipes dehaani Brandt. Indian J Exp Biol. 1983;21:203-7.

21. Liu ZC, Zhang R, Zhao F, et al. Venomic and Transcriptomic Analysis of Centipede Scolopendra subspinipes dehaani. J Proteome Res. 2012;11:6197-212.

22. Zeng $H$, Zhang GG, Cheng JL. Extraction of anti-cancer active components from centipede. Hunan Journal of Traditional Chinese Medicine. 2004;5:57-8.

23. Indran IR, Tufo G, Pervaiz S, et al. Recent advances in apoptosis, mitochondria and drug resistance in cancer cells. Biochim Biophys Acta. 2011;1807:735-45.

24. Tamm I, Schriever F, Dorken B. Apoptosis: implications of basic research for clinical oncology. Lancet Oncol. 2001;2:33-42.

25. Yu J. PUMA Kills Stem Cells to Stall Cancer? Mol Cell Pharmacol. 2009;1:112-8.

26. Sun YL, Jiang WQ, Luo QY, et al. A novel Bcl-2 inhibitor, BM-1197, induces apoptosis in malignant lymphoma cells through the endogenous apoptotic pathway. BMC Cancer. 2019;20:1.

27. Letai A. Puma strikes Bax. J Cell Biol. 2009;185:189-91.

28. Yee KS, Wikinson S, James J, et al. PUMA and Baxinduced autophagy contributes to apoptosis. Cell Death Differ. 2009;16:1135-45.

29. McDonnell TJ, Troncoso P, Brisbay SM. Expression of the protooncogene Bcl-2 in the prostate and its association with emergence of androgen-in-dependent prostate cancer. Cancer Res. 1992;52:6940-4.

30. Babu PP, Suzuki G, Ono Y, et al. Attenuation of ischemia and/or reperfusion injury during myocardial infarction using mild hypothermia in rats: an immunohistochemical study of bcl-2, bax, Bak and TUNEL. Pathol Int. 2004;54:896-903. 
31. Rasul A, Ding C, Li X, et al. Dracorhodin perchlorate inhibits PI3K/AKT and NF-jB activation, upregulates the expression of p53, and enhances apoptosis. Apoptosis. 2012;17:1104-19.

Figures

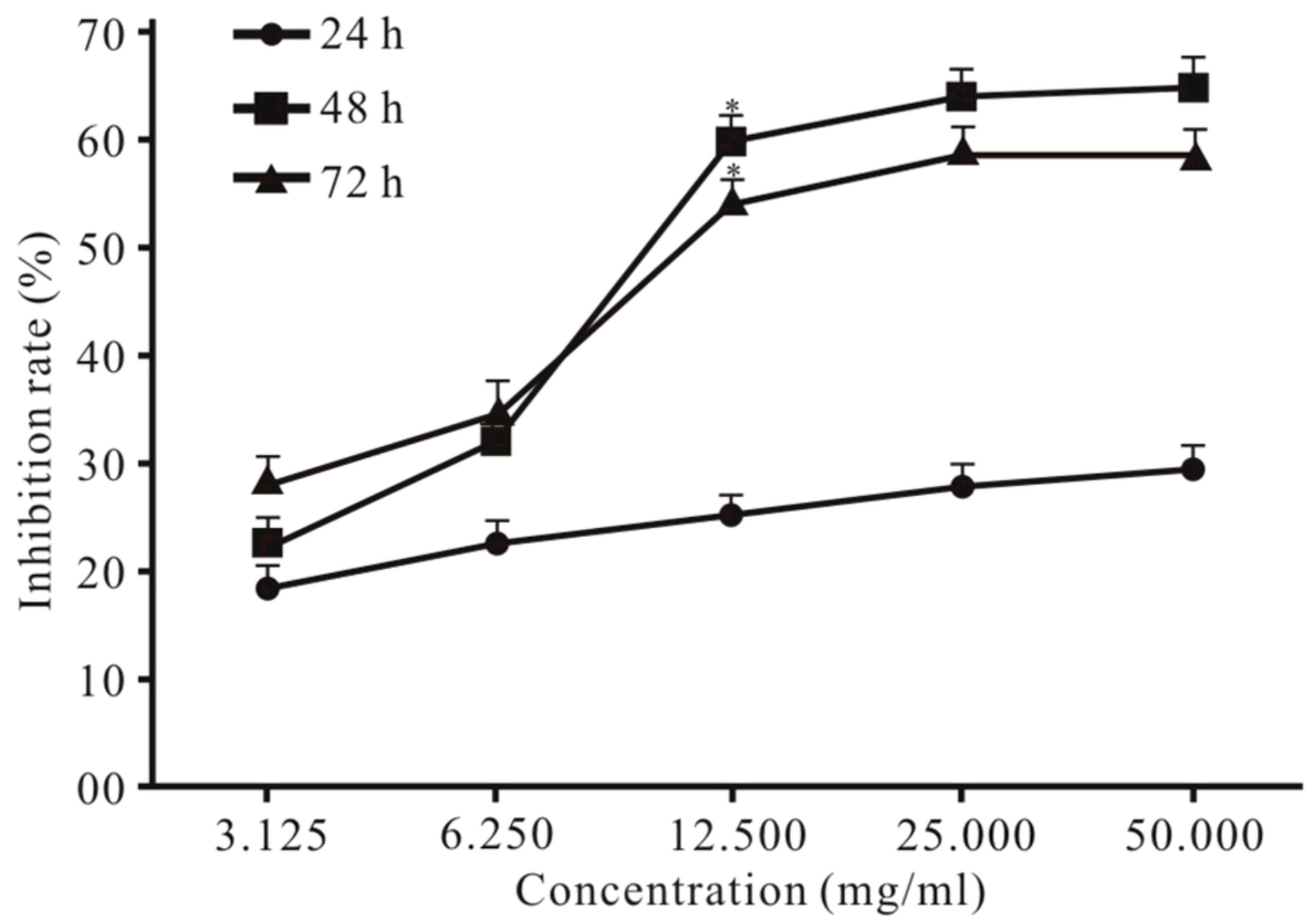

Figure 1

the inhibition rates at different concentration of centipede scolopendra extract in different treatment duration. 

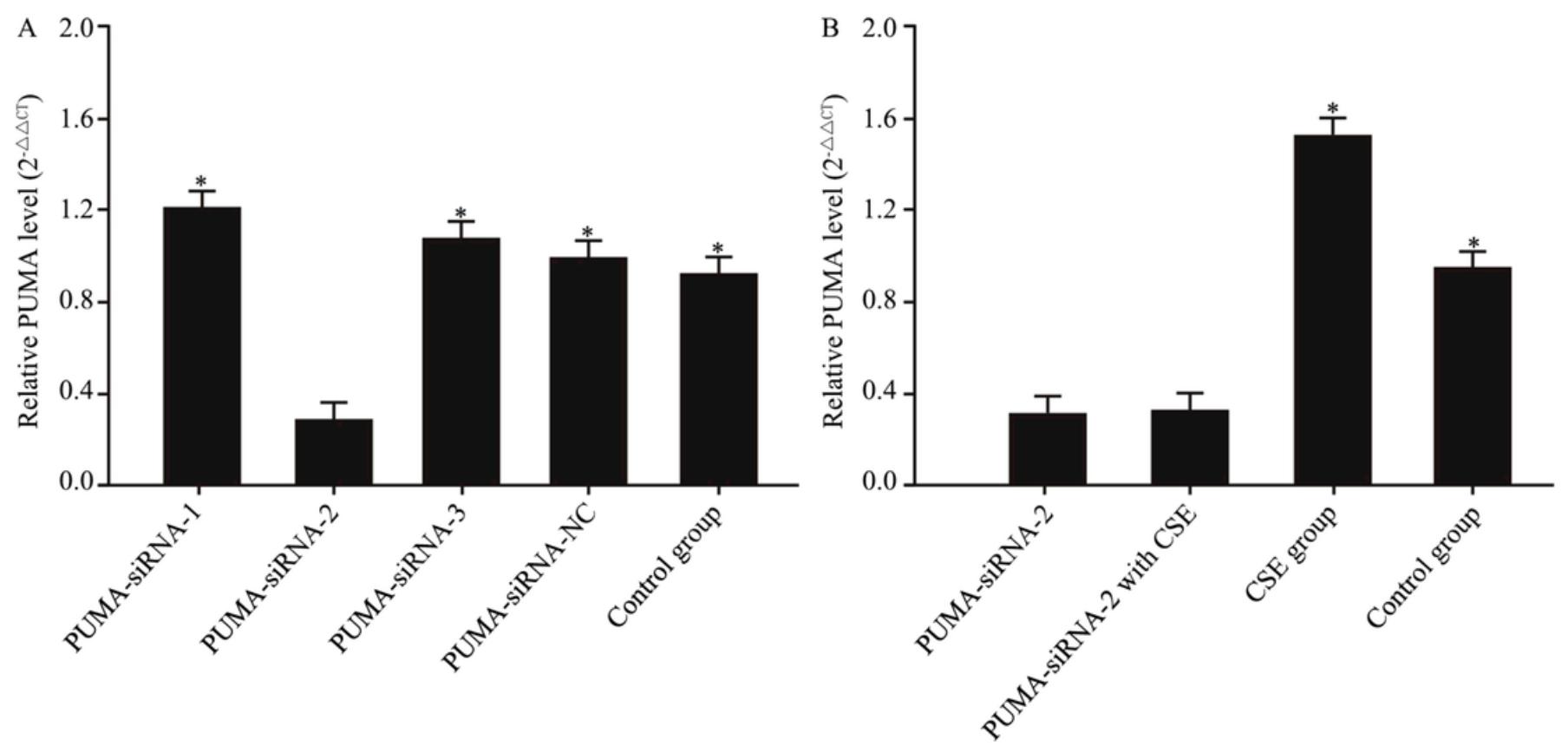

Figure 2

(A) the relative PUMA mRNA expression level in different siRNA groups; (B) the stability of PUMA-siRNA-2 in the presence of centipede scolopendra extract. CSE, centipede scolopendra extract. 

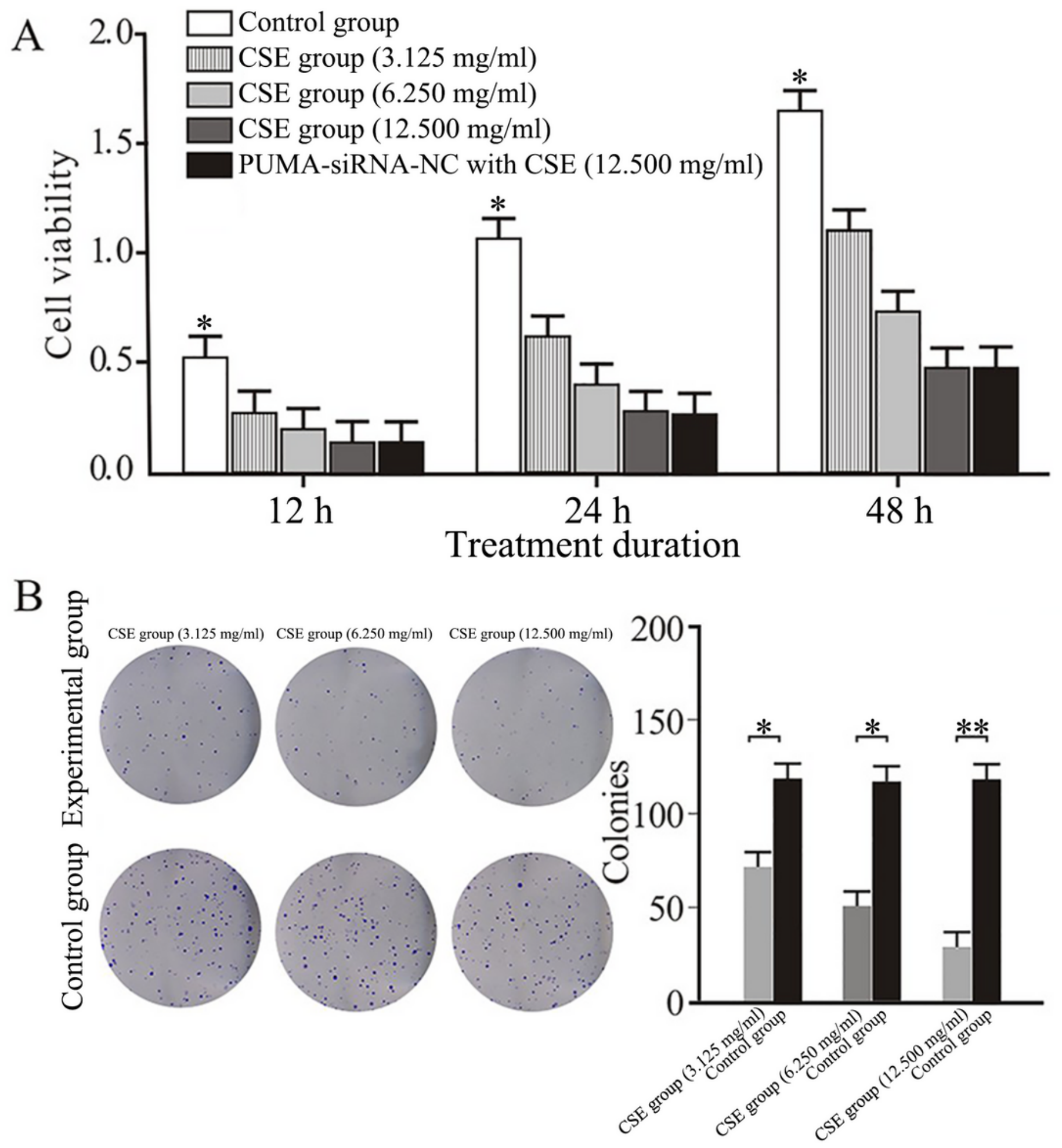

Figure 3

(A) the cell growth ability was markedly inhibited in experimental groups; (B) the cell proliferation ability was markedly inhibited in experimental groups. CSE, centipede scolopendra extract. 

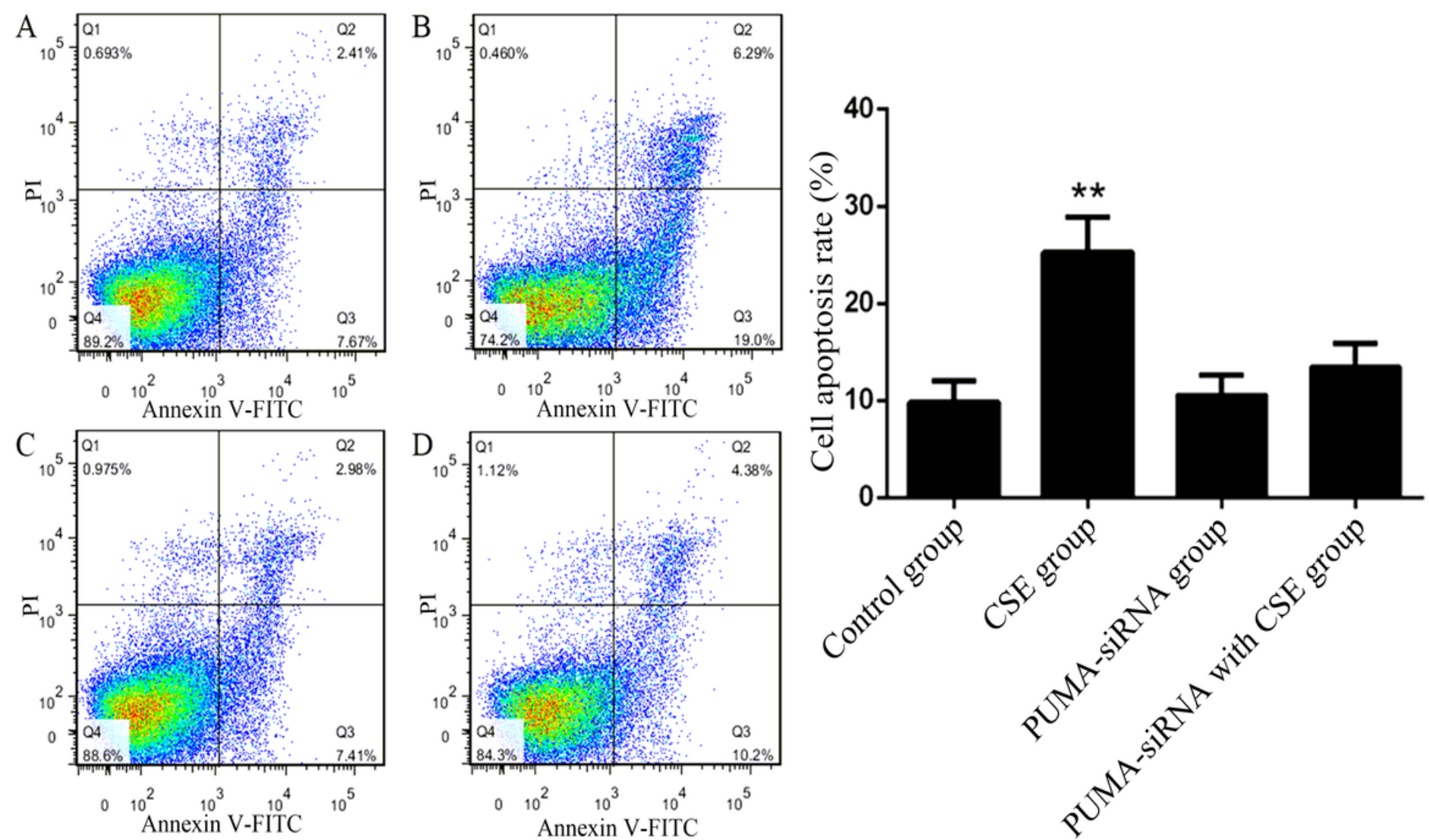

Figure 4

the cell apoptosis in different groups: (A) control group, (B) centipede scolopendra extract group, (C) PUMA-siRNA group, and (D) PUMA-siRNA combined with centipede scolopendra extract group. The later apoptotic cells were in upper right quadrant and the early apoptotic cells were in lower right quadrant, and the sum of the cell percentage in these two quadrants are the cell apoptosis rate. 


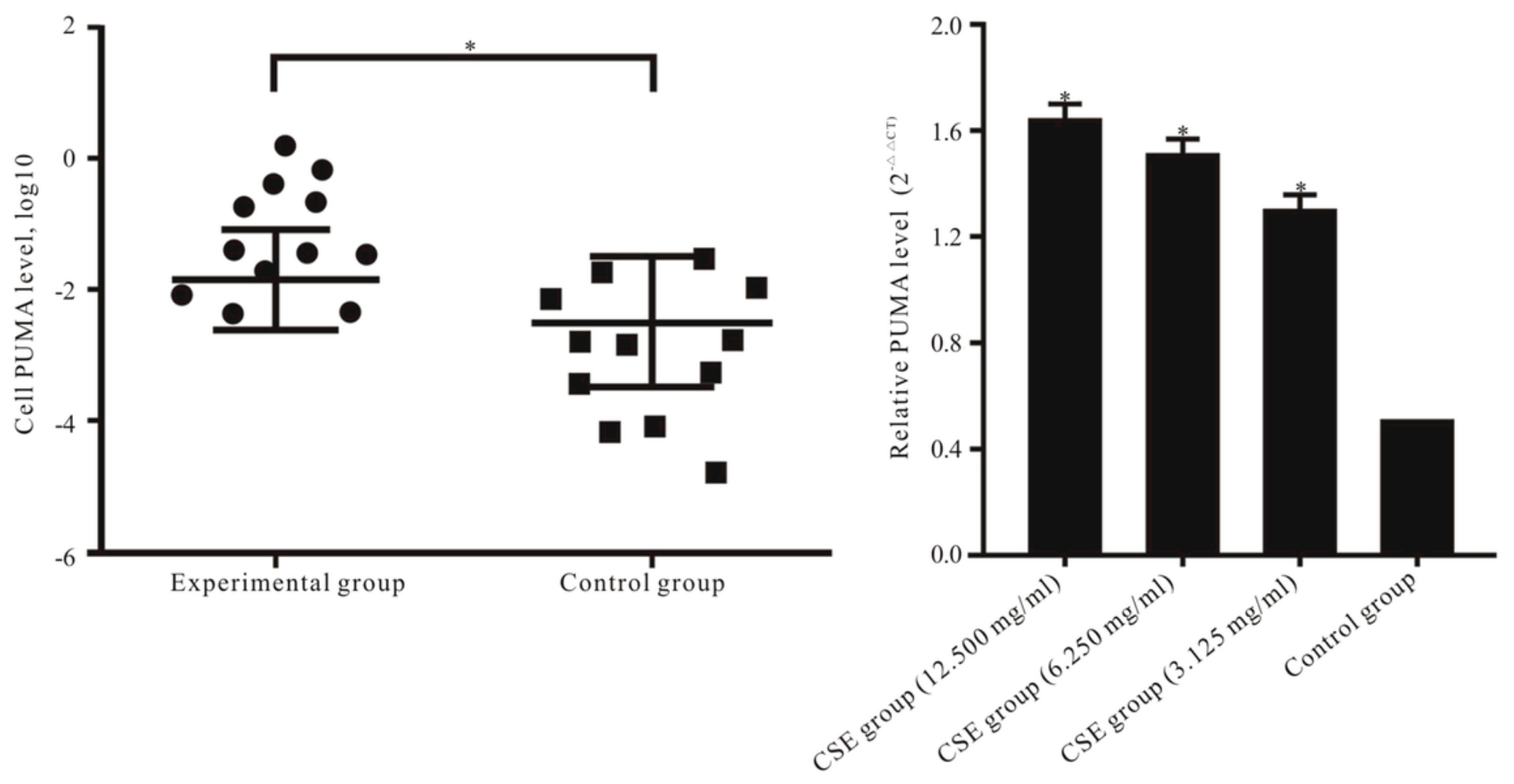

Figure 5

the relative PUMA mRNA expression level in different groups. Compared with the control group, the PUMA expression was markedly increased in the experimental groups $(P<0.05)$. CSE, centipede scolopendra extract.
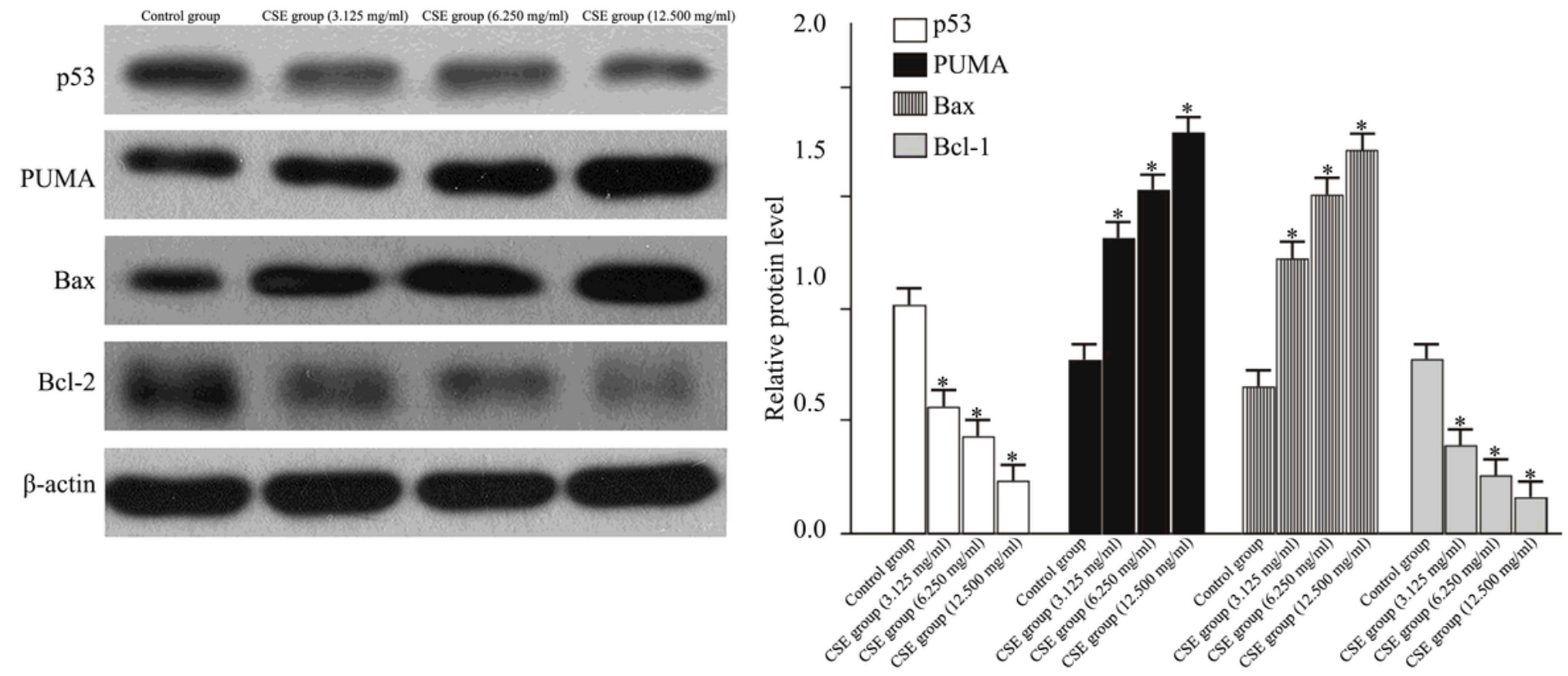

Figure 6 
the relative protein expression level in different groups. Compared with the control group, the PUMA and Bax expression were markedly up-regulated, while the p53 and Bcl-2 expression were markedly downregulated in the experimental groups $(P<0.05)$. CSE, centipede scolopendra extract. 